\title{
A Research on Determining Optimum Splicing Method in Terms of Fiber Types and Yarn Count
}

\author{
Seval Uyanık ${ }^{*}$ \\ Gaziantep University, Technical Sciences Vocational School, Gaziantep Üniversitesi Kampüsü, Şehitkamil, Gaziantep, Turkey
}

Corresponding Author: Seval UYANIK, uyanik@gantep.edu.tr

\begin{abstract}
The quality of the splice made in the yarn is very important in terms of final yarn performance. If yarn ends are not spliced well; the yarn breaking strength and elongation decrease, resulting in too many breaks in the machines during fabric production and consequently low yield. Many methods, which are pneumatic method, the mechanical method, the pneu-mechanical method and electrostatic method, are used for splicing. Among them, pneumatic splicing is the most popular. In this study, it was aimed to investigate spliced yarn performances in terms of three types of splicing methods including air splicing, wet splicing and mechanical splicing known as twin splicing, and to reveal optimum splicing method in terms of fiber type and yarn count. For this aim, a total of twenty seven pure and blended ring-spun yarns containing different raw materials, which were cotton, viscose, polyester, modal and acrylic, were produced with different yarn counts of $\mathrm{Ne} 20$, $\mathrm{Ne} 30$ and $\mathrm{Ne} 40$. Produced yarn samples were spliced in different splicers including air splicer, wet splicer, and twin splicer on Savio Polar IDLS winding machine. The strength and elongation values of spliced yarns were measured with Mesdan-Lab Splice Scanner-3. The measurements were compared to each other and the values before splicing. The study results revealed that twin splicer is the best for cotton fiber and acrylic fiber, whereas it was the worst for regenerated cellulosic fibers. All splicer types can be used for polyester fiber, and the best splicer type is air splicer for fine yarns whereas it is twin splicer for coarse yarns.
\end{abstract}

\author{
ARTICLE HISTORY \\ Received: 07.12.2018 \\ Accepted: 26.12.2018
}

\section{KEYWORDS}

Air splice, wet splice, twin splice, fiber types, yarn count, spliced yarn strength, spliced yarn elongation

\section{Introduction}

The last process of yarn production is winding. The principal objective of winding is to obtain a large package from several small ring bobbins and to cut out unwanted and objectionable faults. Many breaks occur due to regions with low strength in spun yarn during the winding process. Apart from these breaks, yarn clearers make cuts when the specified values are exceeded in order to reach the desired yarn quality. In either case, it is necessary to continue the winding process by splicing or knotting the broken or cut yarn ends. Splicing is the ultimate method to eliminate yarn faults and problems of knots and piecing. It is technique of joining two yarn ends by inter mingling the constituent fibers so that the joint is not significantly different in appearance and mechanical properties with respect to the parent yarn. However, the quality of the splice made in the yarn is very important in terms of final yarn performance although the effectiveness of splicing is primarily dependent on the tensile strength and physical appearance. In cases where the yarn ends are not spliced well, the yarn breaking strength and elongation decrease, resulting in too many breaks in the machines during fabric production and consequently low yield. The knots are responsible for 30 to 60 of stoppages in weaving. In addition, the appearance of splice places also appears to be another issue affecting yarn and fabric quality. The hairs that occur at the splices cause decrease yarn strength as a result of friction, and then increase yarn breaking and loss of efficiency during fabric production, as well as increase in hairiness in the fabric, causing deterioration of appearance and pilling etc. These problems provide for the development of different splicing methods for solution (1-3).

To cite this article: Uyanı S., 2018, "A Research on Determining Optimum Splicing Method in Terms of Fiber Types and Yarn Count" Tekstil ve Konfeksiyon, 29 (1), pp:22-33. 
Many methods are used for splicing. These methods are ordered as the pneumatic method, the mechanical method, the pneu-mechanical method and electrostatic method (4). Among them, pneumatic splicing is the most popular. Other methods have limitations in terms of application, high cost of manufacturing, maintenance and operations, and improper structure and properties of produced yarns.

In the principle of pneumatic splicing, splicing proceeds in two stages with two different air blasts of different intensity (5). The first air blast untwists and causes of free ends. The untwisted fibers are then intermingled and twisted in the same direction as that of parent yarn by another air blast. This basic pneumatic principle of the system allows it to be optimally adapted to the requirements of any desired application with only slight modifications. So that the standard splicer can be converted into thermo splicer, injection splicer and elasto splicer. All these variants are based on the principle of air splicing and their functionality is adapted to suit the specific requirements of the material to be spliced.

The applications of the standard splicer are cotton, cotton blends, polyester, viscose, and cotton compact yarns (1). The use of the injection splicer is recommended for splicing single and plied of vegetable fibers, OE-rotor yarns, cotton compact yarns or yarns with strongly marked inhomogeneous structure or very high twist. The standard pneumatic splicing process is optimized in the addition of a small quantity of water through an electromagnetic dosing valve, which intensifies the effect of the whirling of the fiber ends. The applications of the injection splicer are coarse cotton yarns, plied yarns, OE-rotor yarns, linen yarns and compact yarns. The elasto splicer is especially useful for the splicing of elastic core yarns. This splicer has special braking elements, modified clamping and cutting lines and optimized control software. The elasto splicer can be combined with the injection splicing. The thermo splicer is used for the splicing of wool yarns and blends of them. The pneumatic splicing process is optimized by tuning the splicing air temperature to the specific properties of the yarn.

Mechanical splicing is a less used method compared to pneumatic splicing (6). The first patent in mechanical splicing was developed by Zellweger Uster in 1979. In this process, the broken yarn ends are first automatically untwisted, beards are then formed by pulling the two yarn ends away, and these beards are overlapped and re-twisted together again. The advantages of this method are the absence of air or any extraneous materials, and the reproducibility of the results.

Spliced yarn tensile properties were investigated by many researchers on the basis of yarn parameters including raw material, yarn count, yarn twist etc., splicing parameters and splicing methods in the previous works.

Das et al. (7) investigated fiber friction, and found that the higher the friction between fibers, the higher the compactness of the spliced yarn. Das et al. (8) in the other study examining the effect of the spinning system on the tenacity properties of the spliced yarns demonstrated that the tensile strengths of the spliced sections of ring-spun yarns were better than those of vortex, rotor and frictionspun yarns due to the spiral twist structure of the ring-spun yarns. Webb et al. (9) studied the effects of splicing parameters on the spliced yarn properties and found that the splicing pressure was the most important factor. Lewandowski and Drobina (10) determined that the opening air pressure was the most effective factor on the tensile properties of the spliced yarns, whereas the time of opening and splicing affected their diameter in their study examining the strength and diameter of wool-combed yarns under different splicing conditions. Kaushik et al. (11) indicated that wet splicing gives better property retention than dry splicing; retention of yarn properties in decreasing order was for yarns spun from polyester, polyester-rich blends, viscose, cotton, and wool, respectively; coarse ring spun yarns contribute the most to better spliced yarn properties. Cheng et al. (12), in their study investigating the strength of spliced yarns under different conditions, determined that the length of the yarn tails and the yarn linear density are the parameters that have the most important effect on the strength of spliced yarns. Cheng et al. (13) in the other study examining the strength, bending, abrasion, and appearance properties of spliced yarns under different splicing conditions displayed that yarn linear density is the parameter that has the most important effect on the overall properties of spliced yarns. Nawaz et al. (14) found that the strength properties of the splice region in natural and synthetic blended yarns improve as the synthetic fiber ratio increases. Taşkın et al. (15) and Hassen et al. (6) revealed that the type of splicing mechanism changes the properties of the splice region and wet splicing improves the strength and appearance properties of the splice region. Gurkan Unal et al. (16) tried to determine appropriate splicing settings in order to ensure maximum strength and elongation of yarns with different fiber properties, different number and twist values in air splicing. Gurkan Unal et al. (17) evaluated the retained spliced diameter with regard to splicing parameters and fiber and yarn properties in the next study and found that the fiber diameter, short fiber content, yarn count, yarn twist and opening air pressure affect the retained spliced diameter. Jaouachi et al. (18) in their work defining developed parameters such as the cover factor and the relative distance for quantifying the contribution of Spandex ${ }^{\odot}$ filament position to the spliced yarn appearance investigated the cross-section views of the splice region using the image analysis method. Their findings showed that the Spandex ${ }^{\odot}$ filament angular position is influenced by the important splicing conditions (splice length and duration of water joining) and, by providing the adequate splicing condition adjustments high splice physical performance is given and a particularly good appearance. Wu et al. (19) revealed that pneumatic yarn splicing is a complex process concerning the winding of multi-filaments in a spiral airflow field. They indicated that a proper overlapping length is of benefit to achieve enough winding loops at the free-end of the filament to resist the dragging force exerted by axial airflow and obtain a successful splice subsequently. Celik and Kaynak (20) indicated that the optimum splice pressure for the most appropriate splice appearance changes with respect to the fiber content of the yarn; for 4 and 5 bar splice air pressures, as polyester ratio of the yarn content was increased, the diameter of the splice portion also increased with respect to the diameter of parent yarn, and for 6 bar air pressure, the splice joint diameter decreases with the increase in polyester content of the yarn samples.

In this study, it was aimed to investigate the spliced yarn performances in terms of three types of splicing methods including air splicing, wet splicing and mechanical splicing 
known as twin of pure and blended ring yarns with various fibers and aiming to reveal optimum splicing method in terms of fiber type and yarn count.

It was seen that the effects of splicing parameters on spliced yarns were determined by using air splicing method, and mostly comparison of air splicing and wet splicing were made in the previous studies. Therefore, this study differs from the other studies in terms of comparison of three different splicing methods. Additionally, the usage of different raw materials such as modal, acrylic and different blend ratios such as $80-20 \%$ or $65-35 \%$, and subjective visual analyzes of spliced regions in the yarns as in textile mills has provided innovation and originality to the study. In summary, the examination of many parameters together made a significant contribution to the literature.

\section{Material and Method}

A total of twenty seven pure and blended ring-spun yarns containing different raw materials were produced as $Z$ twisted with different yarn counts having $\mathrm{Ne} 20, \mathrm{Ne} 30$ and $\mathrm{Ne} 40$ at different blend ratios which are 100\%, 80-20\%, 65$35 \%$, and $50-50 \%$. The raw materials were cotton (CO), viscose (CV), polyester (PES), modal (CMD) and acrylic (PAC). The symbols of these fibers given in brackets were used in the text.

Due to the fact that the yarn samples production was very difficult and labor-intensive, a large number of the samples were taken from the existing production types and very few could be produced. Therefore, yarns with blend ratios of $80 / 20 \%$ and $65 / 35 \%$ were not available for modal and acrylic. The facility of the textile mill was to achieve different yarn counts for the same fiber raw material.

The properties of unevenness, imperfection, and hairiness of the obtained yarns were tested in Uster Tester 6 at 400 $\mathrm{m} / \mathrm{min}$ test speed. Yarn tenacity and elongation tests were made in Uster Tensorapid 5 at $5000 \mathrm{~mm} / \mathrm{min}$ test speed and $500 \mathrm{~mm}$ gauge length after all the yarns were conditioned for 24 hours under the standard laboratory conditions according to the ISO 139 standard. The parameters of process machines for spinning, and the properties of the used yarns in the study were given in Table 1 and Table 2, respectively.

Table 1. Machine parameters for spinning

\begin{tabular}{|l|l|l|}
\hline \multirow{3}{*}{ Blow Room } & \multicolumn{2}{|l|}{ Trützschler Blendomat BO-U ( for cotton) } \\
\cline { 2 - 3 } & \multicolumn{2}{|l|}{ Trützschler T-Blend } \\
\cline { 2 - 3 } & Trützschler Tuftomat T0-T1 \\
\cline { 2 - 3 } & Trützschler MX-16 Mixer \\
\hline Card & Trützschler TC 7 & $100 \mathrm{rpm}$ \\
\hline Draw Frame-1 & Trützschler TD 02 & $450 \mathrm{rpm}$ \\
\hline Draw Frame-2 & Trützschler TD 02 & $450 \mathrm{rpm}$ \\
\hline Draw Frame-3 & Trützschler TD 03 & $400 \mathrm{rpm}$ \\
\hline Roving & Oerlikon Zinser 668 & $1100 \mathrm{rpm}$ \\
\hline Ring & Oerlikon Zinser 351 & $18000 \mathrm{rpm}$ \\
\hline Winding & Oerlikon Autoconer 5 & $1200 \mathrm{rpm}$ \\
\hline
\end{tabular}

Table 2. Yarn Properties

\begin{tabular}{|c|c|c|c|c|c|c|c|c|}
\hline $\mathrm{Ne}$ & Yarn type & $\underset{\%}{\mathrm{CVm}}$ & $\begin{array}{l}\text { Thin } \\
-50 \% / \mathrm{km}\end{array}$ & $\begin{array}{c}\text { Thick } \\
+50 \% / k m\end{array}$ & $\begin{array}{c}\text { Neps } \\
+200 \% / k \\
m \\
\end{array}$ & $\begin{array}{c}\text { Hairiness } \\
\mathrm{H}\end{array}$ & $\begin{array}{c}\text { Elongatio } \\
\text { n \% }\end{array}$ & $\begin{array}{c}\text { Tenacity } \\
\text { cN/tex }\end{array}$ \\
\hline \multirow{8}{*}{20} & $100 \% \mathrm{CO}$ & 9.6 & 0 & 2.5 & 4.5 & 4.52 & 6.85 & 17.34 \\
\hline & $100 \% \mathrm{CV}$ & 9.45 & 0 & 4 & 5 & 3.85 & 14.38 & 18.93 \\
\hline & $100 \%$ PES & 9.52 & 0 & 2 & 2 & 4.86 & 12.53 & 30.23 \\
\hline & $80 / 20 \%$ CO/PES & 11.41 & 0 & 10 & 5 & 5.79 & 6.4 & 16.97 \\
\hline & $65 / 35 \%$ CO/PES & 10.6 & 0 & 3.5 & 2 & 5.75 & 7.72 & 18.42 \\
\hline & $50 / 50 \%$ CO/PES & 10.32 & 0 & 1.5 & 0 & 5.32 & 9.5 & 20.00 \\
\hline & $50 / 50 \%$ CO/CMD & 9.76 & 0 & 2 & 3 & 5.32 & 7.49 & 17.76 \\
\hline & $50 / 50 \%$ CO/PAC & 13.18 & 0 & 57 & 34 & 8.29 & 5.64 & 11.92 \\
\hline \multirow{8}{*}{30} & $100 \% \mathrm{co}$ & 11.6 & 0 & 7 & 20 & 4.21 & 5.29 & 17.73 \\
\hline & $100 \% \mathrm{CV}$ & 11.34 & 10 & 9 & 21 & 3.3 & 13.45 & 18.05 \\
\hline & $100 \%$ PES & 11.94 & 3 & 6 & 7 & 4.09 & 10.66 & 28.39 \\
\hline & $80 / 20 \%$ CO/PES & 13.06 & 0.5 & 38.5 & 27.5 & 4.84 & 6.75 & 17.18 \\
\hline & $65 / 35 \%$ CO/PES & 12.72 & 0.5 & 33 & 21.5 & 5.24 & 6.62 & 16.55 \\
\hline & $50 / 50 \%$ CO/PES & 12.43 & 1.5 & 21 & 18 & 4.6 & 9.03 & 20.03 \\
\hline & $50 / 50 \%$ CO/CMD & 11.28 & 0 & 6 & 9.5 & 4.85 & 6.55 & 17.05 \\
\hline & $50 / 50 \%$ CO/PAC & 15.72 & 12 & 242 & 158 & 7.98 & 4.25 & 10.09 \\
\hline & & & & & & & & \\
\hline \multirow{8}{*}{40} & $100 \% \mathrm{CO}$ & 12.44 & 0 & 17.5 & 28.5 & 3.73 & 5.71 & 17.02 \\
\hline & $100 \% \mathrm{CV}$ & 12.80 & 5 & 16 & 31 & 2.92 & 12.08 & 17.30 \\
\hline & $100 \%$ PES & 13.53 & 15 & 124.7 & 24 & 3.48 & 9.94 & 26.65 \\
\hline & $80 / 20 \%$ CO/PES & 14.81 & 20.5 & 94.5 & 80.5 & 4.7 & 4.84 & 15.06 \\
\hline & $65 / 35 \%$ CO/PES & 14.52 & 9.5 & 91.5 & 71 & 4.74 & 6.16 & 15.09 \\
\hline & $50 / 50 \%$ CO/PES & 13.94 & 7 & 63.5 & 46.5 & 4.18 & 6.68 & 18.46 \\
\hline & $50 / 50 \%$ CO/CMD & 12.24 & 0 & 24.5 & 29 & 3.49 & 6.92 & 17.56 \\
\hline & $50 / 50 \%$ CO/PAC & 14.84 & 6 & 102.5 & 196.5 & 6.82 & 5.46 & 13.02 \\
\hline
\end{tabular}


All of the obtained yarn samples were spliced on the same splicing devices on Savio Polar IDLS winding machine. Standard pneumatic splicing devices as air splicer and wet splicer, and twin disc splicer were used for the production of spliced yarns. Splicing parameters of pneumatic and twin splicing used in the study were given in Table 3 and Table 4 , respectively.

Table 3. Splicing parameters used in the study for air and wet splicer

\begin{tabular}{|l|c|}
\hline Parameters & Values \\
\hline The ends preparation blast-T1 & 2 \\
\hline The ends overlap-L & 10 \\
\hline The splicing blast-T2 & 6 \\
\hline Air pressure-P & 6 bar \\
\hline
\end{tabular}

T1- The duration of the blast. It is adjustable from 1 to 12 (1 is the shortest blast)

L- Overlap length. It is adjustable from 1 to 12.1 corresponds to minimum overlapping (short splice); 12 corresponds to maximum overlapping (long splice)

T2- The air blast, adjustable in time. It is adjustable from 1 to 12 (1 is the shortest blast)
Table 4. Splicing parameters used in the study for twin splicer

\begin{tabular}{|l|c|}
\hline Parameters & Code \\
\hline Untwisting-U & 5 \\
\hline Re-twisting-R & 3 \\
\hline Drafting-D & 2 \\
\hline
\end{tabular}

U-R- They are adjustable from 1 to 7 (1 is the lowest strength)

D- It adjusts splice diameter. It is adjustable from 0 to 4 (Diameter decreases from 0 to 4 )

In the first stage, the breaking strength and elongation of yarns before splicing were measured in Mesdan-Lab Splice Scanner-3 test device having the gage length was $250 \mathrm{~mm}$ and test speed was $100 \mathrm{~m} / \mathrm{min}$ according to the TS $245 \mathrm{EN}$ ISO 2062 standard. In the second phase, the splicing units as wet splicer and twin disc splicer were placed on Savio Polar IDLS winding machine having air splicers, and after this process the splicing process was carried out for these yarns in each splicer unit for a certain period of time. After each splice, the breaking strength and elongation values of spliced yarns were measured with the same device. These tests were repeated as ten times for each splice unit and yarn. The measurement results in test device before and after splicing were shown in Table 5 . In addition to this, a comparative visual analysis was performed by photographing the spliced places after splicing in each splice unit.

Table 5. Strength and elongation before and after splicing

\begin{tabular}{|c|c|c|c|c|c|c|c|c|c|}
\hline \multirow{2}{*}{ Yarn type } & \multirow{2}{*}{$\begin{array}{l}\text { Yarn } \\
\text { count }\end{array}$} & \multicolumn{4}{|c|}{ Strength (kg) } & \multicolumn{4}{|c|}{ Elongation (\%) } \\
\hline & & Yarn* & Air & Wet & Twin & Yarn ${ }^{*}$ & Air & Wet & Twin \\
\hline \multirow{3}{*}{$100 \%$ CO } & $\mathrm{Ne} 20$ & 510 & 339 & 358 & 457 & 4.9 & 2.92 & 2.84 & 3.68 \\
\hline & $\mathrm{Ne} 30$ & 301 & 233 & 251 & 300 & 3.31 & 2.3 & 2.41 & 2.79 \\
\hline & $\mathrm{Ne} 40$ & 238 & 179 & 206 & 206 & 2.8 & 2.14 & 2.64 & 2.45 \\
\hline \multirow{3}{*}{$100 \% \mathrm{CV}$} & $\mathrm{Ne} 20$ & 519 & 476 & 409 & 449 & 13.06 & 11.98 & 10.6 & 10.37 \\
\hline & $\mathrm{Ne} 30$ & 322 & 310 & 249 & 234 & 12.26 & 11.68 & 8.63 & 6.87 \\
\hline & $\mathrm{Ne} 40$ & 331 & 313 & 172 & 174 & 10.37 & 10.02 & 7.62 & 6.02 \\
\hline & & & & & & & & & \\
\hline \multirow{3}{*}{$100 \%$ PES } & $\mathrm{Ne} 20$ & 880 & 783 & 699 & 738 & 11.04 & 10.1 & 8.39 & 9.4 \\
\hline & $\mathrm{Ne} 30$ & 552 & 446 & 483 & 479 & 9.09 & 7.76 & 7.98 & 8.41 \\
\hline & $\mathrm{Ne} 40$ & 422 & 383 & 368 & 361 & 9.49 & 8.34 & 7.97 & 7.63 \\
\hline & & & & & & & & & \\
\hline \multirow{3}{*}{$80-20 \%$ CO/PES } & $\mathrm{Ne} 20$ & 500 & 330 & 367 & 479 & 5.35 & 3.56 & 4.24 & 5.53 \\
\hline & $\mathrm{Ne} 30$ & 320 & 251 & 319 & 314 & 4.62 & 3.41 & 4.68 & 4.11 \\
\hline & $\mathrm{Ne} 40$ & 232 & 196 & 222 & 221 & 4.3 & 3.64 & 4.26 & 3.44 \\
\hline \multirow{3}{*}{$65-35 \%$ CO/PES } & $\mathrm{Ne} 20$ & 493 & 371 & 459 & 514 & 6.6 & 4.7 & 6.19 & 6.38 \\
\hline & $\mathrm{Ne} 30$ & 314 & 271 & 297 & 323 & 5.15 & 3.91 & 4,78 & 4.58 \\
\hline & $\mathrm{Ne} 40$ & 231 & 181 & 190 & 224 & 5.14 & 3.94 & 4.44 & 4.92 \\
\hline & & & & & & & & & \\
\hline \multirow{3}{*}{$50-50 \%$ CO/PES } & $\mathrm{Ne} 20$ & 604 & 485 & 508 & 623 & 9.19 & 7.54 & 7.68 & 8.68 \\
\hline & $\mathrm{Ne} 30$ & 376 & 323 & 340 & 371 & 7.48 & 6.18 & 6.86 & 6.9 \\
\hline & $\mathrm{Ne} 40$ & 263 & 231 & 250 & 257 & 5.63 & 5.1 & 5.92 & 5.07 \\
\hline & & & & & & & & & \\
\hline \multirow{3}{*}{$50-50 \% \mathrm{CO} / \mathrm{CMD}$} & $\mathrm{Ne} 20$ & 470 & 368 & 418 & 456 & 6.5 & 4.06 & 4.92 & 4.94 \\
\hline & $\mathrm{Ne} 30$ & 312 & 276 & 241 & 265 & 5.22 & 4.43 & 3.48 & 3.53 \\
\hline & $\mathrm{Ne} 40$ & 241 & 191 & 204 & 207 & 4.06 & 2.94 & 3.36 & 3.01 \\
\hline \multirow{3}{*}{$50-50 \%$ CO/PAC } & $\mathrm{Ne} 20$ & 304 & 258 & 289 & 321 & 3.8 & 3.44 & 4.29 & 4.43 \\
\hline & $\mathrm{Ne} 30$ & 208 & 172 & 169 & 190 & 5.02 & 3.42 & 3.57 & 3.42 \\
\hline & $\mathrm{Ne} 40$ & 172 & 139 & 133 & 166 & 3.2 & 2.52 & 2.44 & 2.84 \\
\hline
\end{tabular}

*Before splicing 
Analyses of variance (ANOVA) in order to determine the relationships between the independent variables and the dependent variables, and correlation tests determining the strength of relationship were applied. For this aim the statistical software package SPSS 22 was used to interpret the experimental data. All test results were assessed at $95 \%$ confidence interval.

\section{Results and Discussion}

\section{Splice Strength}

From Figure 1 it is clear that twin splicing gives the highest strength value whereas air splicing causes the lowest strength value, and also splicing strength values of air splicing and wet splicing are close to each other after splicing for all yarns containing cotton fiber except CV yarn and PES yarn. It is thought that the reason for this is that the length of cotton fiber is shorter than the others, and as a result the short fibers are partially re-twisted instead of completely holding together due to the effect of the pressurized air. On the contrary twin splicing, which is mechanical splicing, is much more effective as the discs come into direct contact with the fibers to allow the yarn to twist, and because there is no pressure and thus the distribution of short fibers is prevented. On the other hand, wet splicing is better than air splicing since water prevents fiber separation during pressure application. The values of yarn strength and elongation given in Table 5 also reveal that twin splicing has the best results, air splicing has the worst results. Additionally, twin splice strength is surprisingly higher than yarn strength which is before splicing, in the yarns of $65-35 \%$ CO/PES, $50-50 \%$ CO/PES, and $50-50 \%$ $\mathrm{CO} / \mathrm{PAC}$. Moreover, the strength difference between before and after splicing decreases in parallel with decreasing of cotton fiber in the yarns for air and wet splicing. These differences are the lowest for $50-50 \%$ CO/PAC yarn especially.

For CV yarn and PES yarn containing pure man-made fibers, air splicing has the highest strength values whereas wet splicing has the lowest strength values, and all splicing strength values are lower than that of yarn strength. The reason for this is that the fiber length of $C V$ and PES is enough for air splicing in comparison to cotton fiber, and also the yarns having these fibers have smooth surface, and are therefore slippery, and in addition to this twin splicer increases slippage with mechanical contact.

Based on Figure 2, it is observed that twin splicing ensures the highest strength for $100 \% \mathrm{CO}, 65-35 \% \mathrm{CO} / \mathrm{PES}, 50-$ $50 \%$ CO/PES, and $50-50 \%$ CO/PAC, whereas air splicing in $100 \%$ CV and $50-50 \%$ CO/CMD, and wet splicing in $100 \%$ PES and $80-20 \%$ CO/PES gives the best strength. Air splicing has the lowest strength in 100\% CO, 100\% PES and the blended yarns containing CO/PES, whereas wet splicing in 50-50\% CO/CMD and 50-50\% CO/PAC, and twin splicing in $100 \%$ CV has the lowest ones.

According to Figure 3, unlike those observed for $\mathrm{Ne} 20$ and $\mathrm{Ne} 30$, the effectives of wet splicing and twin splicing are almost the same for the yarns containing cotton fiber, and these splice types have the highest strength values except $65-35 \%$ CO/PES yarn and 50-50\% CO/PAC yarn.

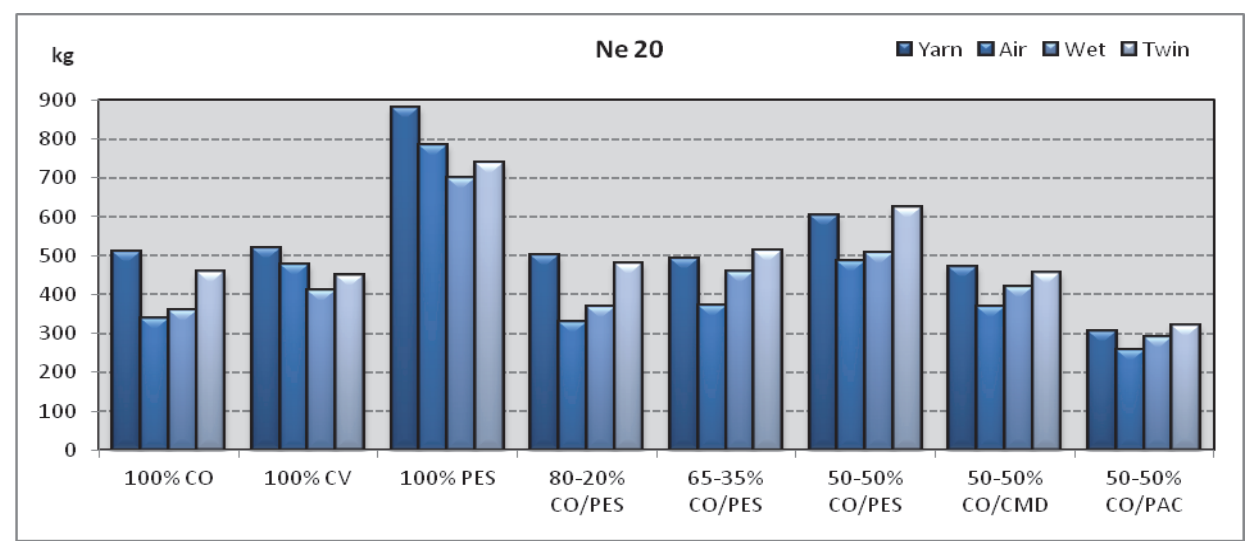

Figure 1. Splice strength for $\mathrm{Ne} 20$

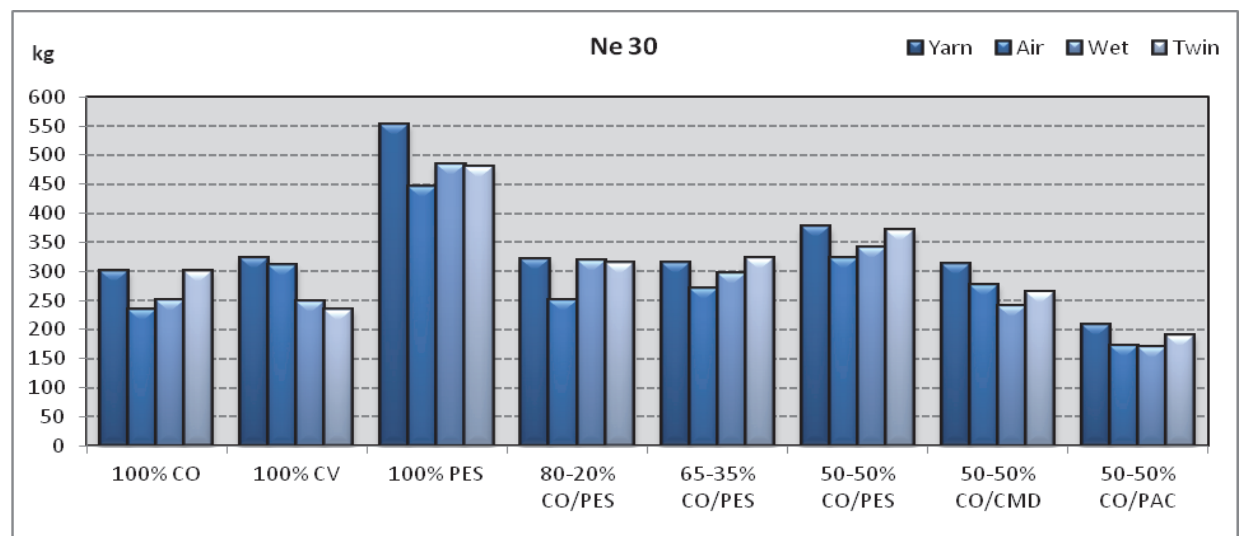

Figure 2. Splice strength for $\mathrm{Ne} 30$ 


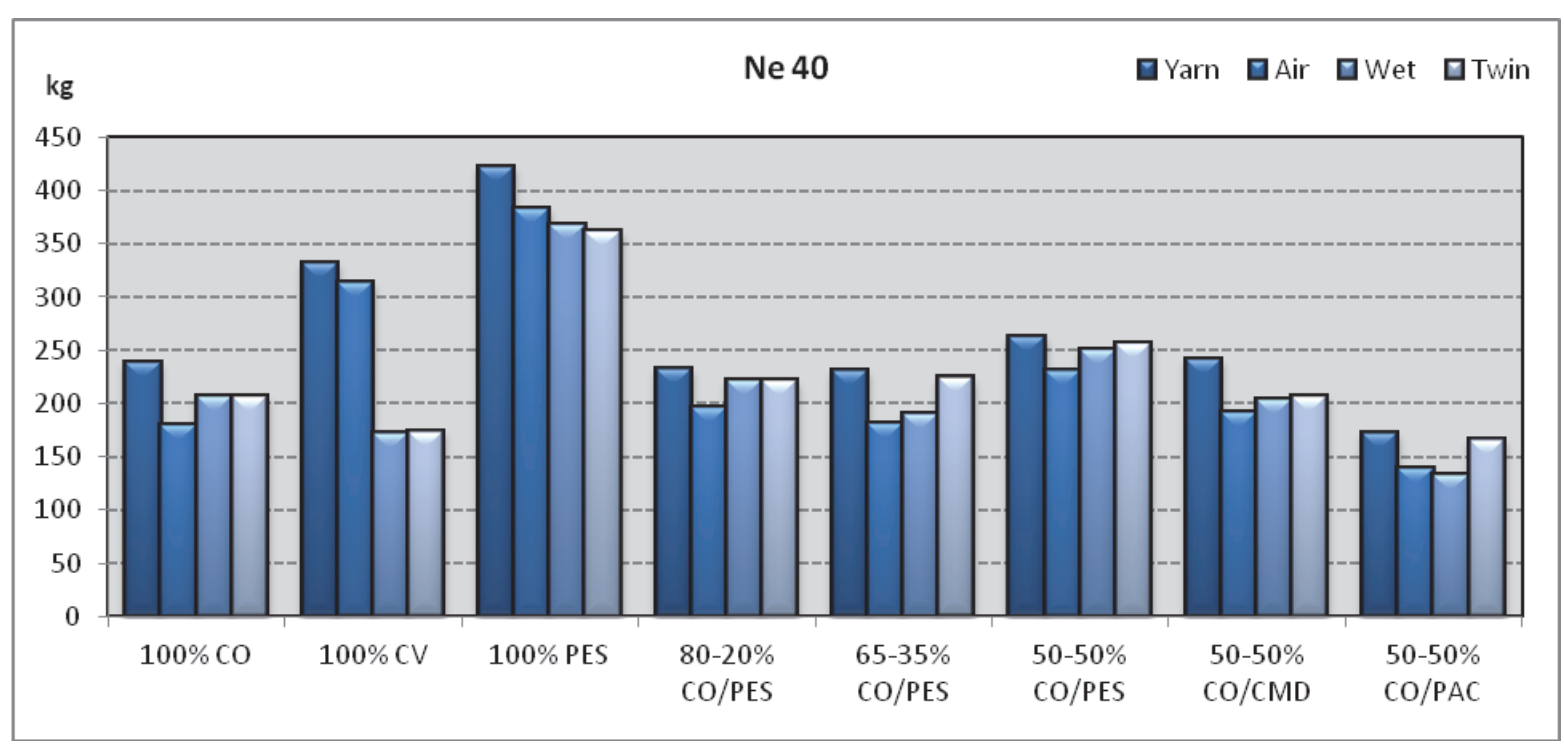

Figure 3. Splice strength for $\mathrm{Ne} 40$

As for the mentioned yarns, twin splicing has the best results, air splicing has the worst results for $65-35 \%$ CO/PES yarn, and air splice and wet splice is the same for $50-50 \%$ CO/PAC yarn. On the contrary, air splice has the highest values whereas twin splice has the lowest values for $\mathrm{CV}$ yarn and PES yarn as become in $\mathrm{Ne} 20$ and $\mathrm{Ne} 30$.

ANOVA results given in Table 6 support all findings. Table 6 shows that yarn count and all fiber types except modal fiber have significant effect on strength for air splicing and twin splicing. On the other, the effect of CMD is not significant on strength for all splicer types, although $\mathrm{CV}$ has not significant effect for only wet splicing. Based on F values, PES and PAC are the most effective fibers for all splicing types, and the effect of $\mathrm{CO}$ is more for only air splicing.
There are strongly correlations according to the correlation test results (Table 7) determining the strength and direction of the relationship between factors and the strength of spliced yarn. These correlations are positive for PES, whereas they are negative for the others in all splicing types except CV. As for CV, correlation is positive for air splicing, on the contrary it is negative for wet splicing and twin splicing.

Considering coefficient strength, it is possible to say that air splice is the best for fine yarns, whereas twin splice is the worst for these yarns, twin splice is the best for $\mathrm{CO}$ and PAC, wet splice is the best for PES and CMD, air splice is the best for CV.

Table 6. ANOVA results for strength

\begin{tabular}{|l|r|r|r|r|r|r|}
\hline \multirow{2}{*}{ Factors } & \multicolumn{6}{|c|}{ Strength } \\
\cline { 2 - 8 } & \multicolumn{3}{|c|}{ Air } & \multicolumn{2}{c|}{ Wet } & \multicolumn{2}{c|}{ Twin } \\
\cline { 2 - 8 } & F & Sig. & F & Sig. & F & Sig. \\
\hline $\begin{array}{l}\text { Yarn } \\
\text { count }\end{array}$ & 63.567 & 0.000 & 99.171 & 0.000 & 169.841 & 0.000 \\
\hline CO & 28.050 & 0.000 & 8.355 & 0.000 & 3.503 & 0.008 \\
\hline PES & 37.771 & 0.000 & 36.420 & 0.000 & 23.302 & 0.000 \\
\hline CV & 4.918 & 0.028 & 3.006 & 0.084 & 5.704 & 0.018 \\
\hline CMD & 2.050 & 0.154 & 1.575 & 0.211 & 2.120 & 0.147 \\
\hline PAC & 29.022 & 0.000 & 29.835 & 0.000 & 23.986 & 0.000 \\
\hline
\end{tabular}

Table 7. Correlation test results for strength

\begin{tabular}{|l|l|l|l|}
\hline \multirow{2}{*}{ Factors } & \multicolumn{3}{|c|}{ Strength } \\
\cline { 2 - 4 } & \multicolumn{1}{|c|}{ Air } & Wet & Twin \\
\hline $\begin{array}{l}\text { Yarn } \\
\text { count }\end{array}$ & $-.576^{* *}$ & $-.664^{* *}$ & $-.747^{* *}$ \\
\hline CO & $-.513^{* *}$ & $-.300^{* *}$ & $-.185^{* *}$ \\
\hline PES & $.574^{* *}$ & $.613^{* *}$ & $.531^{* *}$ \\
\hline CV & $.142^{*}$ & -.112 & $-.153^{*}$ \\
\hline CMD & -.092 & -.081 & -.094 \\
\hline PAC & $-.330^{* *}$ & $-.334^{* *}$ & $-.303^{* *}$ \\
\hline
\end{tabular}

"Correlation is significant at 0.01 level.

"Correlation is significant at 0.05 level.
All findings including figures and statistical analysis clearly reveal that twin splicing is usually the most appropriate for the yarns containing cotton fiber as pure and blended in terms of splice strength. Wet splicing is also positive for these yarns after twin splicing. Air splicing is only observed as appropriate for $\mathrm{CV}$ yarn and PES yarn as pure, and $\mathrm{CO} / \mathrm{CMD}$ blended yarn having regenerated cellulosic fiber.

\section{Splice Elongation}

According to Figure 4, as become in strength, twin splicing provides the highest breaking elongation to yarns containing cotton fiber after splicing. On the other hand, elongation values of all splicing types are close to each other for these 
yarns. In CO/PES blended yarns and $50-50 \%$ CO/PAC yarn, elongation values of twin splicing are close to yarn elongation which is before splicing, and furthermore these values are higher than yarn elongation for $80-20 \% \mathrm{PES} / \mathrm{CO}$ yarn and $50-50 \%$ CO/PAC yarn. The lowest elongation value is in twin splicing for $\mathrm{CV}$ yarn, and it is in wet splicing for PES yarn whereas air splicing has the highest elongation value for both of them. In wet and twin splicing, the reason for this is slippage due to yarn smoothness was explained before.

Figure 5 exhibits that air splice has the lowest elongation except the yarns containing regenerated cellulosic fibers. Although twin splice has the highest elongation in 100\% CO, $100 \%$ PES, $50-50 \%$ CO/PES, and wet splice has the highest elongation in $80-20 \%$ CO/PES, $65-35 \%$ CO/PES, $50-50 \%$ CO/PAC, these values are very close to each other. Thus, it cannot be said that wet splice or twin splice is better than the others for these yarns. It is clear that twin splice is the worst elongation for $100 \% \mathrm{CV}$ due to mechanical slippage during splicing between discs. As for $50-50 \%$
$\mathrm{CO} / \mathrm{CMD}$, cotton content in the yarn reduces this negative situation and so that twin splice and wet splice is seen as equal.

According to Figure 6 , wet splicing ensures the highest elongation, and the values of air splice and twin splice are very close to each other for the yarns containing cotton fiber except $65-35 \%$ CO/PES yarn and $50-50 \%$ CO/PAC yarn, whereas the splicing type which gives the highest value is air splicing for CV yarn and PES yarn. For $65-35 \%$ CO/PES yarn and $50-50 \%$ CO/PAC yarn, twin splice is the best. It is noticed that the elongation values of spliced yarns are not too low compared to splicing before except $\mathrm{CV}$ yarn and PES yarn.

Based on ANOVA results given in Table 8 , it can be said that yarn count and all fiber types have significant effect on elongation for all splicer types. In terms of $F$ values, the most effective fibers are $\mathrm{CV}$ and $\mathrm{CO}$ for both air splicing and wet splicing. As for twin splicing, the effect of $\mathrm{CO}$ is remarkable though the other $F$ values are not very different.

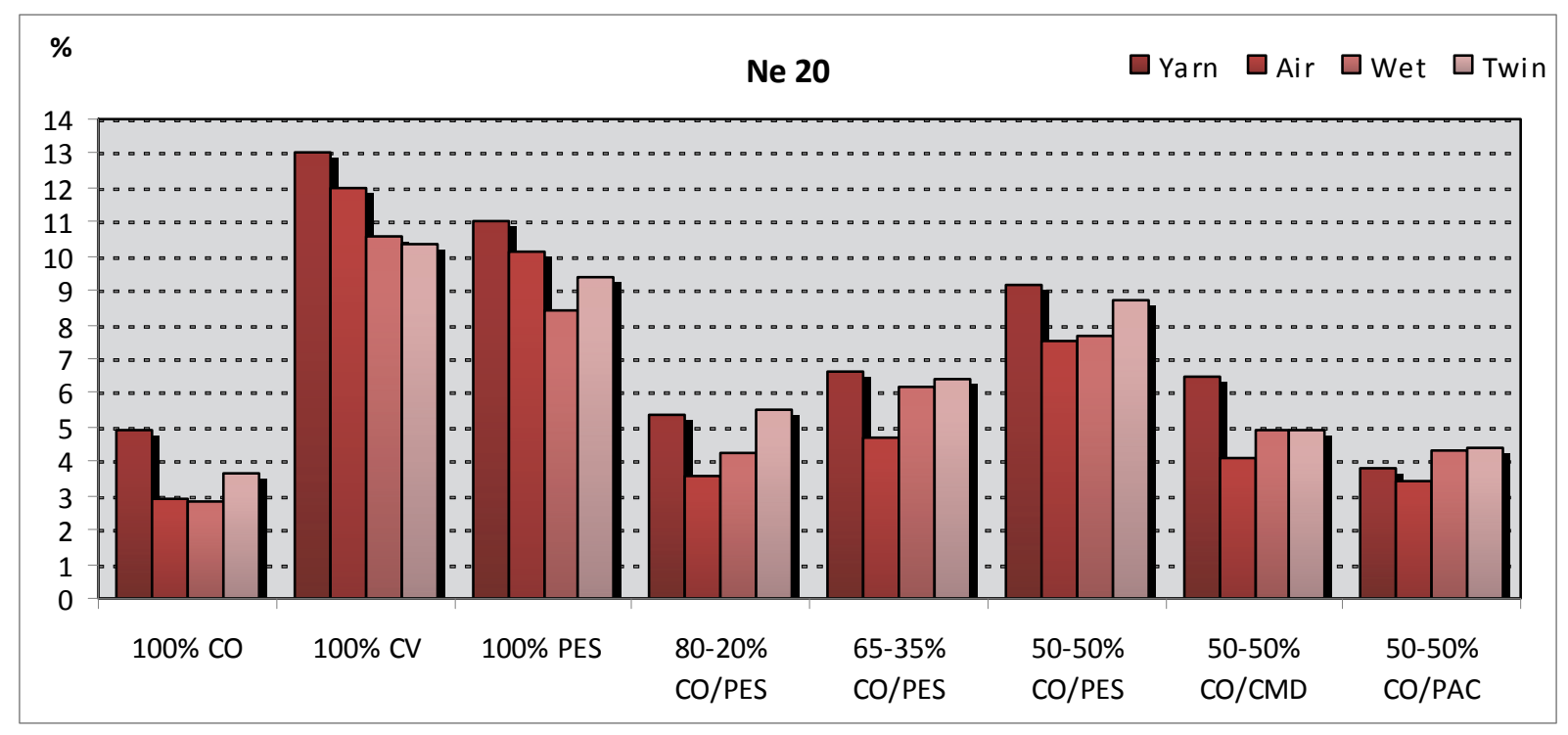

Figure 4. Splice elongation for $\mathrm{Ne} 20$

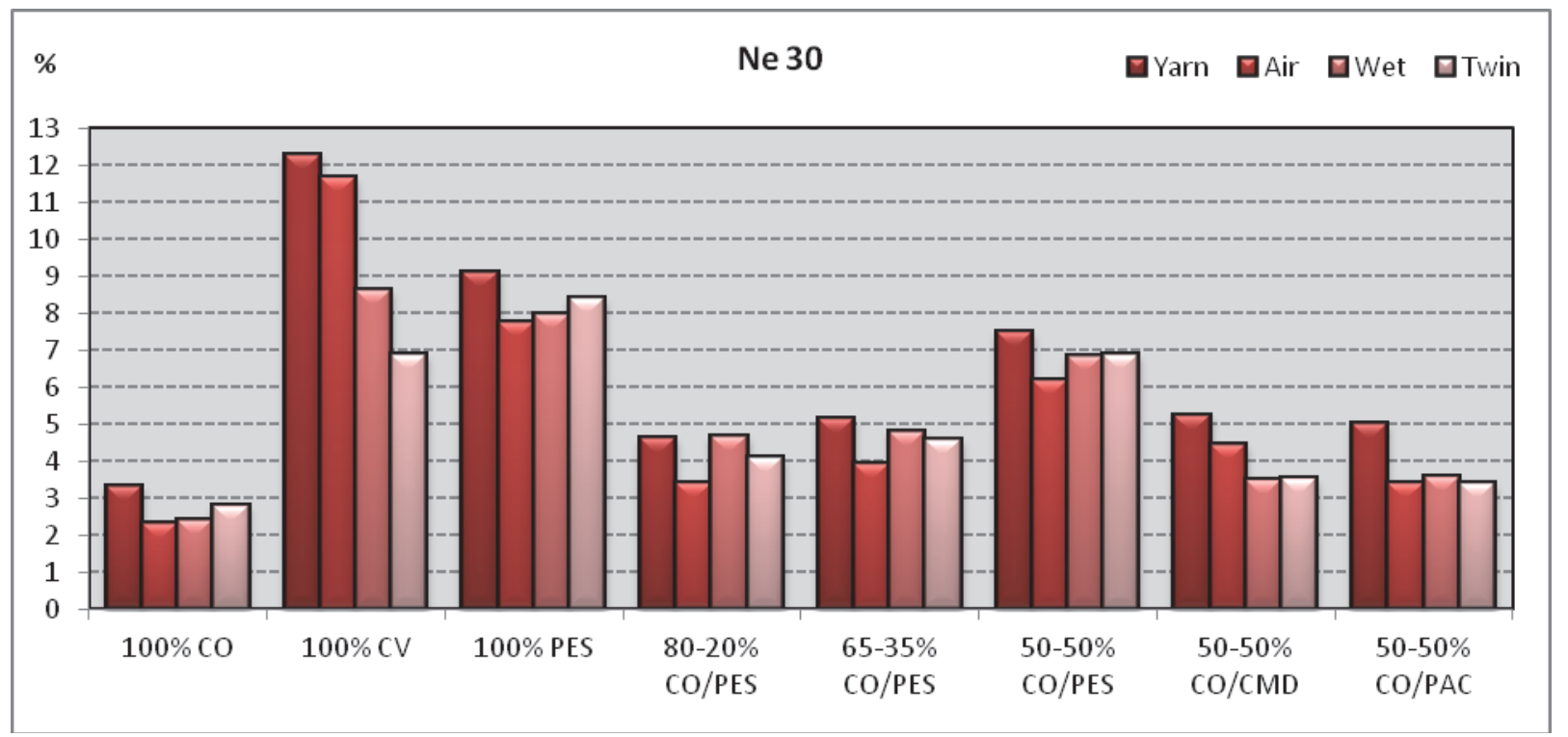

Figure 5. Splice elongation for $\mathrm{Ne} 30$ 


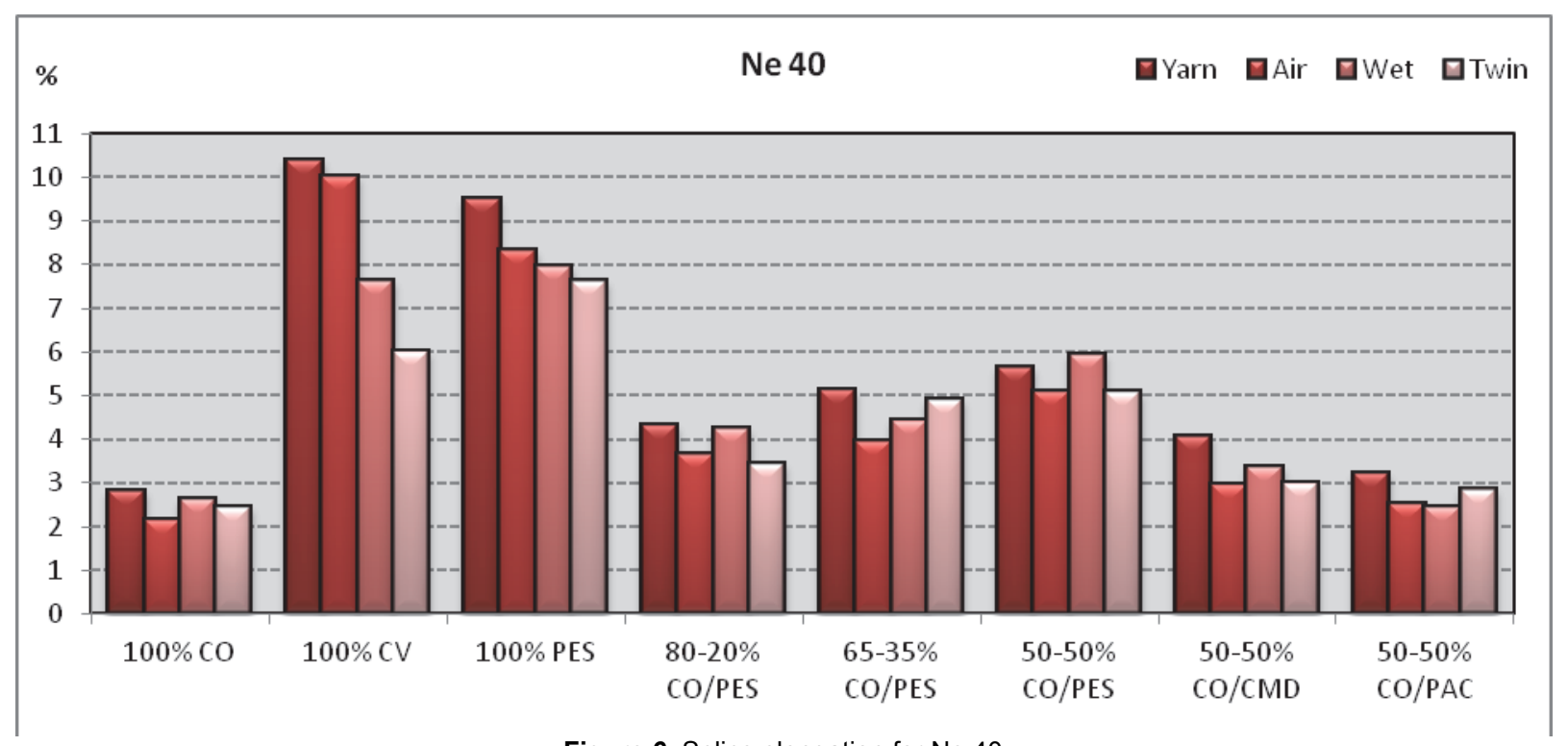

Figure 6. Splice elongation for $\mathrm{Ne} 40$

Table 8. ANOVA results for elongation

\begin{tabular}{|l|r|r|r|r|r|r|}
\hline \multirow{2}{*}{ Factors } & \multicolumn{6}{|c|}{ Elongation } \\
\cline { 2 - 7 } & \multicolumn{2}{|c|}{ Air } & \multicolumn{2}{|c|}{ Wet } & \multicolumn{2}{c|}{ Twin } \\
\cline { 2 - 7 } & F & Sig. & F & Sig. & F & Sig. \\
\hline $\begin{array}{l}\text { Yarn } \\
\text { count }\end{array}$ & 3.025 & 0.050 & 6.193 & 0.002 & 22.470 & 0.000 \\
\hline CO & 175.271 & 0.000 & 97.917 & 0.000 & 61.756 & 0.000 \\
\hline PES & 15.969 & 0.000 & 20.345 & 0.000 & 31.986 & 0.000 \\
\hline CV & 232.544 & 0.000 & 101.271 & 0.000 & 39.437 & 0.000 \\
\hline CMD & 9.128 & 0.003 & 13.693 & 0.000 & 15.733 & 0.000 \\
\hline PAC & 19.293 & 0.000 & 25.064 & 0.000 & 22.151 & 0.000 \\
\hline
\end{tabular}

Likewise, correlation test results given in Table 9 demonstrate that the most strongly correlations are between $\mathrm{CO}$ and splicing types, and are negative. The correlations between PES and splicing types, and between CV and splicing types are positive and strongly, while they are negative and less strongly for the other factors and splicing types. When evaluated correlation coefficients, the findings gives meaning air splice is the best for fine yarns, CV, CMD and PAC. Conversely, the best splicing type is twin splice for $\mathrm{CO}$ and PES.

Table 9. Correlation test results for elongation

\begin{tabular}{|l|c|c|c|}
\hline \multirow{2}{*}{ Factors } & \multicolumn{3}{|c|}{ Elongation } \\
\cline { 2 - 4 } & \multicolumn{1}{|c|}{ Air } & Wet & Twin \\
\hline $\begin{array}{l}\text { Yarn } \\
\text { count }\end{array}$ & $-.157^{*}$ & $-.220^{* *}$ & $-.388^{* *}$ \\
\hline CO & $-.825^{* *}$ & $-.758^{* *}$ & $-.685^{* *}$ \\
\hline PES & $.346^{* *}$ & $.474^{* *}$ & $.569^{* *}$ \\
\hline CV & $.703^{* *}$ & $.546^{* *}$ & $.377^{* *}$ \\
\hline CMD & $-.192^{* *}$ & $-.233^{* *}$ & $-.249^{* *}$ \\
\hline PAC & $-.274^{* *}$ & $-.309^{* *}$ & $-.292^{* *}$ \\
\hline
\end{tabular}

"Correlation is significant at 0.01 level. "Correlation is significant at 0.05 level.

\section{Analysis of Photographic Views of Spliced Yarns}

In the following figures, the photographic views of spliced yarns are given after each splicer on the basis of yarn count.

Splice photo images exhibits that wet splice has very hairy views; air splice has partially thin places along splice region although it has less hairy views, and twin splice has much smooth, hairless and larger diameter views for all yarns. Expectedly, air splicing and wet splicing has worse performance since hairy places of splicing cause loss strength and elongation in the yarns. In other way, these hairy places are proof that the fibers do not get enough retwisting due to low fiber adhesion. As for air splicing, thin places in splice region show the lowest fiber adhesion depending on the reduced number of fibers in the yarn cross-section. For $\mathrm{CV}$ yarn and PES yarn, it is noticed that air splicing has good splice performance, and twin splicing has bad splice performance although air splice has the worst splice views, and twin splice has the best splice views. This situation is resulted from that these fibers are slippery, which causes the fibers to slide between the discs and consequently fiber-fiber adhesion is not ensured enough as explained before. Twin splice view of $100 \%$ PES yarn for $\mathrm{Ne}$ 20 can be given as example for this. In other way, this figure shows negative view indicating that the yarn ends are not sufficiently re-twisted. 

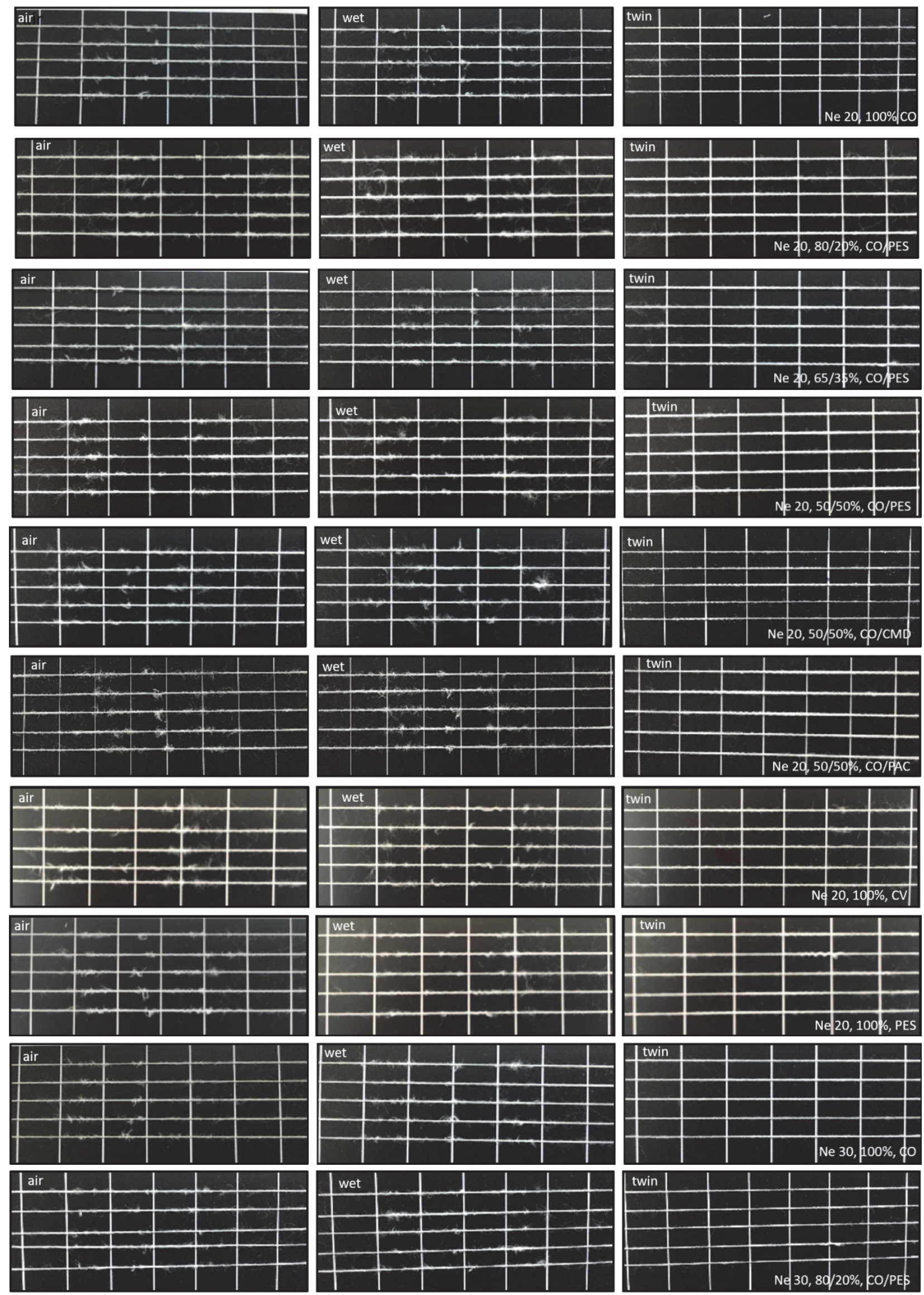

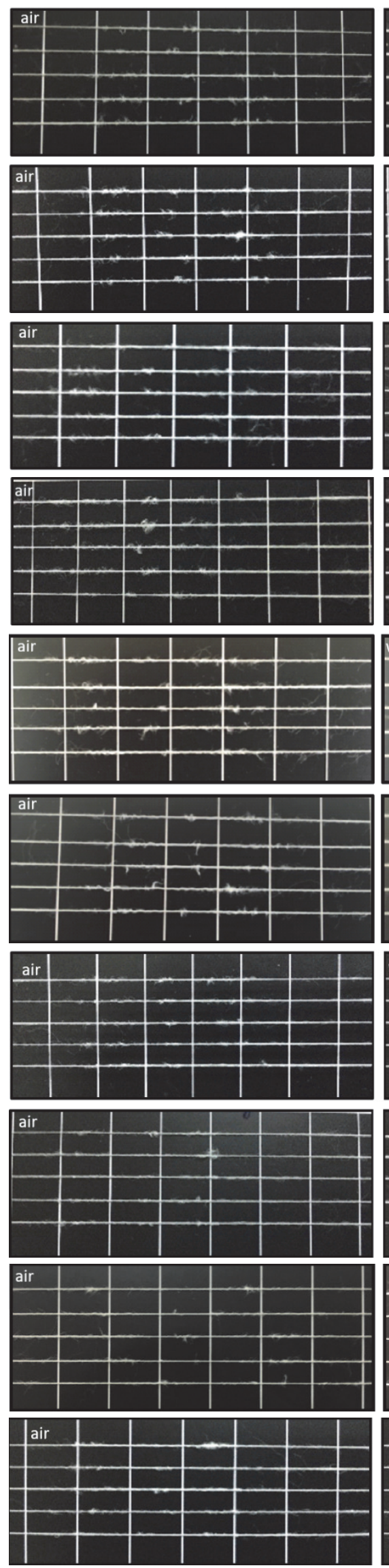
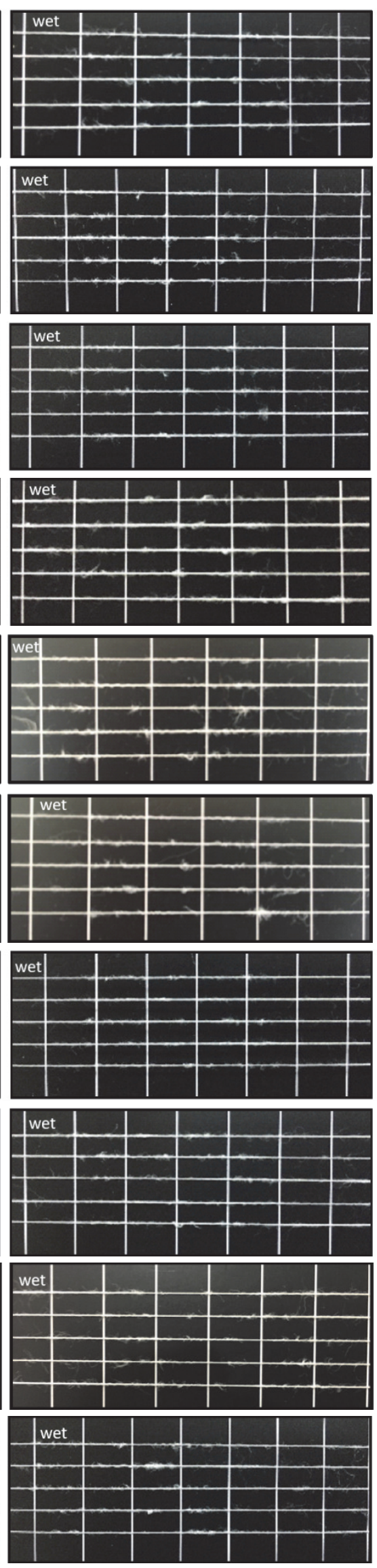
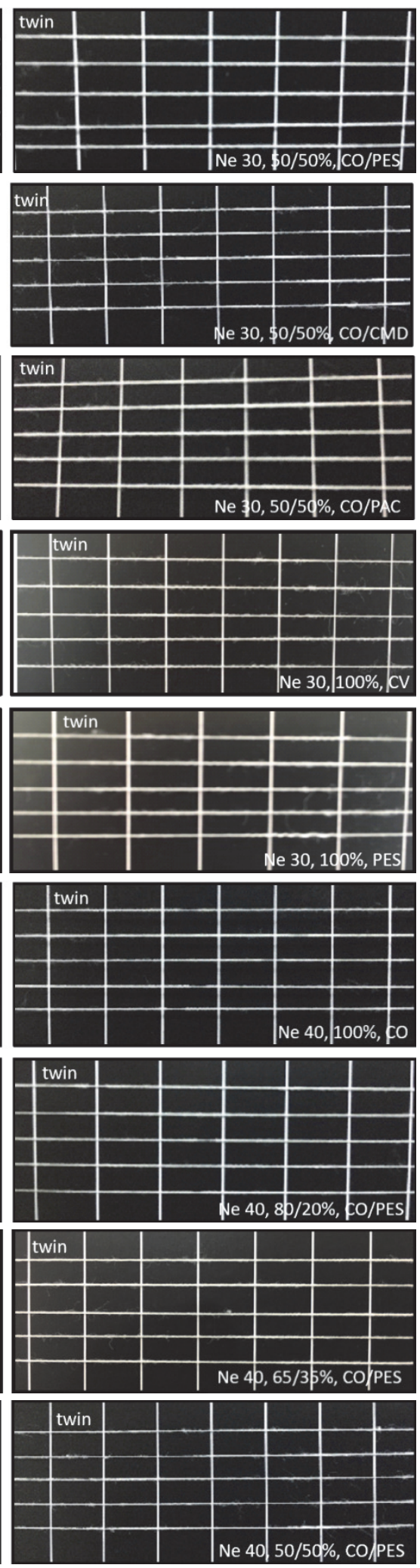

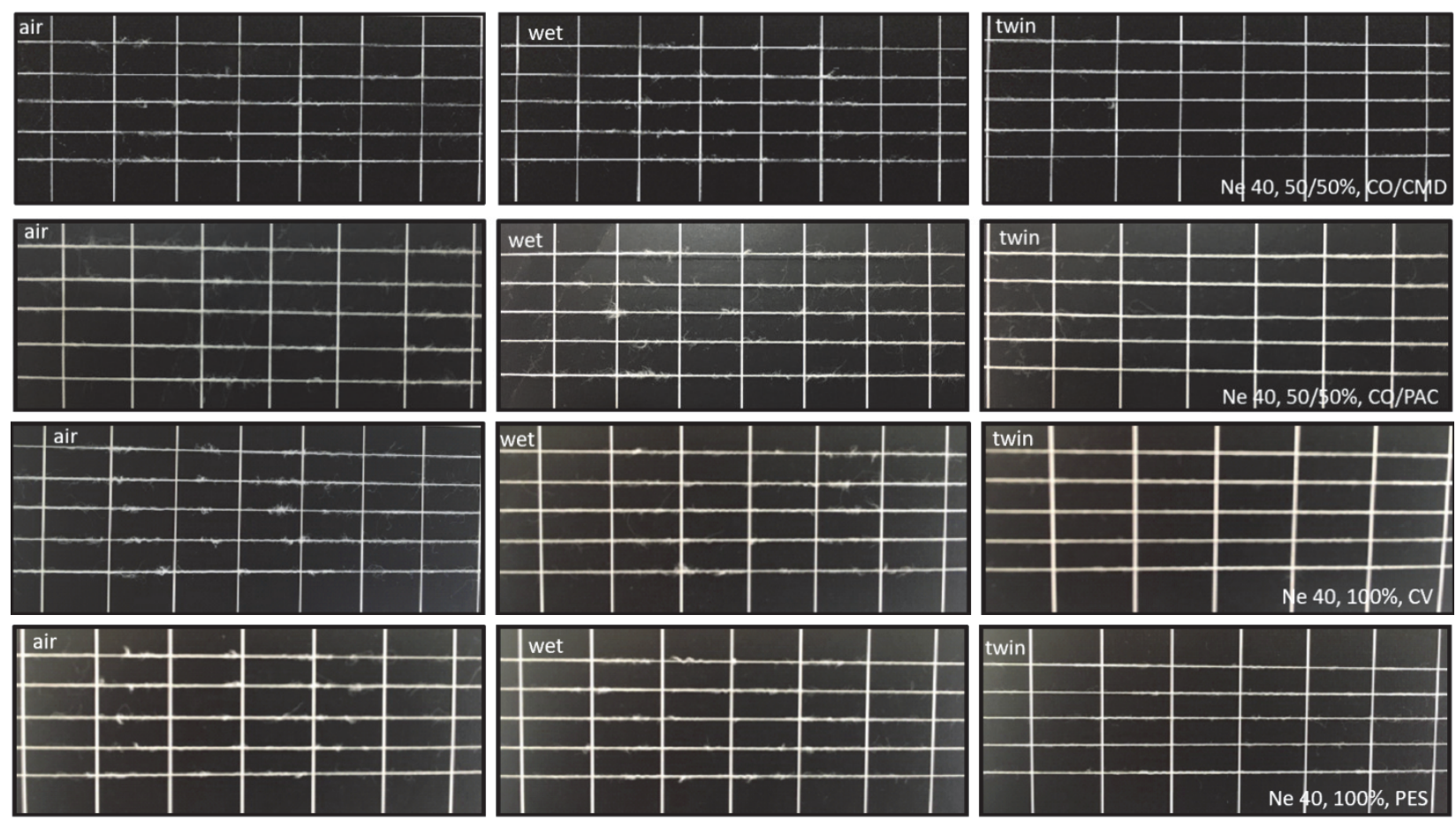

Figure 7. Photographic views of spliced yarns

\section{Conclusion}

It is aimed that optimum splicing method is revealed in terms of yarn count and fiber type with this study. The findings exhibited that yarn count and fiber type could play a decisive role for splicer selection.

When considered yarn count as factor, it is possible to say that optimum splicers are different for fine yarns and coarse yarns. The optimum splicer type is air splicer for fine yarns due to much effective splicing pressure in parallel with decreasing of the fibers in yarn cross-section, whereas it is twin splicer for coarse yarns since the yarn ends are retwisted effectively thanks to contacting twin discs to fibers.

The optimum splicer type is twin splicer for the yarns containing cotton fiber due to twin splicing is much more effective as the twin discs come into direct contact with fibers that require to be twisted in the yarn ends, and also there is no air pressure and thus the separation of short fibers is prevented. The most negative splicer type is air splicer for the yarns containing cotton fiber because of the cotton fiber is short and these short fibers are partially retwisted instead of completely adhesion due to the effect of the pressurized air. Additionally wet splicer is better than air splicer since water, ensuring fiber adhesion, prevents fiber separation from yarn cross section during pressure application, and especially this splicer type is the best for fine yarns in terms of splice elongation. These findings are also supported by splice photographs views with air splice having hairy and partially thin places, wet splice having hairy, and twin splice having much smooth, hairless and partially larger yarn diameter.

Air splicer is the most appropriate splicer type for especially for fine yarns containing the regenerated cellulosic fibers, which are viscose and modal, when splice strength and elongation are evaluated together. Twin splicer is not proper since these fibers have smooth surface and are therefore slippery, and in addition to this twin splicer increases slippage with mechanical contact although splice views is very positive.

As for polyester fiber, it cannot be say that only one splicer type is optimum since the graphical analysis and statistical analysis do not exactly match. However, it is possible say that air splicer and wet splicer looks a bit more appropriate than twin splicer in terms of splice strength, whereas twin splicer is more appropriate than the others in terms of splice elongation. When splice strength and splice elongation is considered together, it can be interpreted that all splicer types are appropriate for polyester fiber.

It can be said that acrylic fiber has behavior like a cotton fiber in terms of splicing types. Namely, twin splicer is optimum splicer type for this fiber due to it is not slippery such as viscose fiber and modal fiber; and because of not showing static electricity like polyester fiber.

As a result, twin splicer should be preferred for the yarns containing cotton fiber and acrylic fiber, whereas this splicer type is not absolutely proper for the yarns containing regenerated cellulosic fibers, and the yarns containing polyester fiber can be spliced with all splicer types. Finally, air splicer for fine yarns, and twin splicer for coarse yarns can be suggested in terms of optimum splicing.

\section{ACKNOWLEDGEMENT}

The author thanks to ŞIRECI TEKSTIL for splicing processes and spliced yarn performance tests, also SELÇUK IPLIKK for the yarns manufacturing. 


\section{REFERENCES}

1. http://textilecentre.blogspot.com.tr/2014/01/different-splicing-systems-used-in.html (Date of access: 23.11.2017)

2. https://schlafhorst.saurer.com/fileadmin/Schlafhorst/pdf/Spulen/ACX5_Brochure_Saurer_en.pdf. (Date of access: 25.01.2018)

3. Taşkın C., Baykaldı B., Gürkan P., 2006, “The Comparison Of Pneumatic And Injection Elastosplicers For Cotton/Elastane Yarns In Winding Process", Textile and Clothing, 3: 185-189.

4. Issa K., Grütz R., 2005, "New Technique For Optimising Yarn-End Preparation On Splicer, And A Method For Rating The Quality Of Yarn End", AUTEX Research Journal, 5: 1-19.

5. http://textilesindepth-textilewinding.blogspot.com/2010/09/splicing.html (Date of access: 25.01.2018)

6. Hassen M.B., Jaouachi B., Sahnoun M., Sakli F., 2008, "Mechanical Properties and Appearance of Wet-Spliced Cotton/Elastane Yarns", Journal of Textile Institute, 99(2): 119-123.

7. Das A., Ishtiaque S.M., Parida J.R., 2005, "Effect of Fiber Friction, Yarn Twist and Splicing Air Pressure on Yarn Splicing Performance", Fibers Polymers, 6(1): $72-78$.

8. Das A., Ishtiaque S.M., Nagaraju V., 2004, "Study on Splicing Performance of Different Types of Staple Yarns”, Fibers Polymers, 5(3): $204-208$.

9. Webb C.J., Waters G.T., Thomas A.J., Liu G.P., Thomas C., 2007, "The Influence of Yarn Count on the Splicing of Simple Continuous Filament Synthetic Yarns", Textile Research Journal, 79(3): 195-204

10. Lewandowski S., Drobina R., 2004, "Strength and Geometric Sizes of Pneumatically Spliced Combed Wool Ring Spun Yarns", Fibres \& Textiles in Eastern Europe, 12(2): 31-37.

11. Kaushik R.C.D, Sharma I.C., Hari P.K., 1987, "Effect of fiber yarn variables on mechanical properties of spliced yarn”, Textile Research Journal, $57: 490-494$.

12. Cheng K.P.S., Lam H.L.I., 2000, “Strength of Pneumatic Spliced Polyester/Cotton Ring Spun Yarns”, Textile Research Journal, 70(3): $243-246$.

13. Cheng K.P.S., Lam H.L.I., 2000, “Physical Properties of Pneumatically Spliced Cotton Ring Spun Yarns”, Textile Research Journal, $70(12): 1053-1057$.

14. Nawaz M., Farooq A., Tosief M., Shahbaz B., 2005, "Effect of Some Splicing Variables upon Strength Characteristics of Polyester/Cotton Blended Yarns", Journal of Agriculture and Social Sciences, 1(1): 35-37.

15. Taskin C., Baykaldı B., Gurkan P., 2004, Elastan Karışımlı İpliklerin Bobinlenmesinde İplik Uç Birleştirme (Splicing) İşlemini Etkileyen Parametrelerin Incelenmesi, TUBITAK TAM Projesi.

16. Gurkan Unal P., Ozdil N., Taskin, C., 2010, "The Effect of Fiber Properties on the Characteristics of Spliced Yarns: Part I: Prediction of Spliced Yarns Tensile Properties", Textile Research Journal, 80(5): 429-438.

17. Gurkan Unal P., Arikan C., Ozdil N., Taskin, C., 2010, "The Effect of Fiber Properties on the Characteristics of Spliced Yarns: Part II: Prediction of Retained Spliced Diameter", Textile Research Journal, 80(17): 1751-1758.

18. Jaouachi B., Ben Hassen M., Sahnoun M., et al., 2010, "Evaluation of Wet Pneumatically Spliced Elastic Denim Yarns With Fuzzy Theory", Journal of Textile Institute, 101: 111-119.

19. Wu Z., Shi P., Chen S., Jin Y., Hu X., 2015, "Study on Effects of Structural Parameters on Untwisting Performance in Pneumatic Yarn Splicing", Textile Research Journal, 85(17): 1776-1788.

20. Celik H.I., Kaynak H.K., 2017, "Effect Of Fiber Blending Ratios of Cotton/Polyester Yarns on Retained Splice Diameter", IOP Conference Series: Materials Science and Engineering. 254142005 